\title{
Best available techniques for oil spill containment and clean-up in the Mediterranean Sea
}

\author{
F. Cumo ${ }^{1}$, F. Gugliermetti ${ }^{1} \&$ G. Guidi ${ }^{2}$ \\ ${ }^{1}$ Department of Technical Physics, Sapienza University of Rome, Italy \\ ${ }^{2}$ ENEA, Department of Fusion and Nuclear Technologies, Italy
}

\begin{abstract}
An oil spill is the accidental or intentional release of petroleum products into the environment as a result of human activity (drilling, manufacturing, storing, transporting, waste management). Oil spills are unfortunately common events in many parts of the world. A survey has been undertaken on Best Available Techniques (BATs) used both for oil spill prevention and oil spill response. Preventing oil spill is definitely the best strategy for avoiding potential damage to human health and the environment. Nevertheless, when a spill occurs, the best approach for containing and controlling the spill is to take action quickly and in a well-organized and efficient way. The aim of the paper is the proposal of evaluation criteria aiming at an optimal BAT determination when an oil spill occurs. The criteria are referred to BATs for oil spill containment and to BATs for clean up of marine habitat, with particular regard to the item of the preservation of biodiversity.

Keywords: BAT, oil spill, clean up.
\end{abstract}

\section{Introduction}

This work has been carried out in the framework of a research activity, concerning the marine environment defence and the loss of biodiversity as a consequence of spills in maritime oil transport, in cooperation with the Italian Ministry of Environment. An oil spill is the accidental or intentional release of petroleum products into the environment as a result of human activities (drilling, manufacturing, storing, transporting, waste management) [1]. This kind of event is not unusual and happens all over the world. Even if oil spills are actually just a 
small percent of the total world oil pollution problem, they represent the most visible form of it. Oil spills give rise to many problems throughout the world. The impact on the ecosystem in an area can be severe as well as the impact on economic activities. The cleaning-up of oil spills is a very difficult and expensive activity.

\section{Oil spill prevention techniques}

Preventing oil spill is the best strategy for avoiding potential damage to human health and to the environment. Clean up is time consuming and expensive, but clean-up costs are minor compared to the negative impact on an organization's brand and image. Repetitive oil spills, even minor ones, lead to increased scrutiny from environmental regulators. Prevention measures are intended to avoid the release of oil into the environment and are based upon:

- early warning systems;

- $\quad$ satellite monitoring systems.

An early warning system is able to detect spills and leaks of oil-on-water. It can provide 24-hour real-time detection of even small quantities of hydrocarbons and is reliable in rough weather or night conditions, when traditional inspection techniques are ineffective. Early detection enables responding authorities to take immediate corrective actions to stop and contain a spill, thereby offering an effective means of minimizing the environmental and financial impact of a spill event [2].

Earth observation satellites turn out to be more and more often an essential prevention and control tool, especially if it is employed together with standard observation techniques. By means of satellites a global coverage is possible instead of the more local coverage of an aircraft. In order to prevent and control oil spills it could be useful a satellite monitoring system, based upon the use of one of the available channels of Galileo, the new European Satellite Navigation System. It will allow a quick and efficient surveillance and detection of oil spills that today is unthinkable. The use of this technique could discourage illegal oil releases and could allow an accurate localization of particularly heightened risk areas and routes.

Among the prevention techniques should be also taken into account what foreseen in the so-called "Erika packages" [3]. Actually, following the Erika accident, the European Commission prepared measures to increase maritime safety. In March 2000 the Commission adopted a first set of proposals (Erika I package), followed by a second one in December 2000 (Erika II package). The Erika I package reinforces the inspection regime and raises the quality requirements for the classification of societies. It also set a timetable for phasingout single-hull oil tankers. As a matter of fact double-hull tankers offer better protection for the environment, in the event of an accident. The Erika II package establishes a European Maritime Safety Agency, responsible for improving enforcement of the EU rules on maritime safety. Moreover, the package establishes a surveillance and information system to improve vessel monitoring in EU water, proposes a mechanism to improve compensation for victims of oil 
spills and raises the upper limits on the amounts payable in the event of major oil spills in EU waters.

\section{Oil spill containment techniques}

When oil falls into water, it tends to spread and cover as much of the available water surface as possible. The size of the oil-covered surface will depend on factors such as the quantity of oil, its viscosity and the weather conditions [4]. It is critical to contain the spill as quickly as possible, in order to minimize danger to persons, environment and property. Containment techniques are used to limit the spread of oil and to allow for its recovery, removal or dispersal and are based upon mechanical containment.

The most common type of equipment, used to control the spread of oil, is the booms. They are used for concentrating oil in thicker surface layers, making its recovery easier as well as for keeping oil out of sensitive areas or for diverting oil into collection areas.

There are many kinds of booms but all boom types are greatly affected by the conditions at sea: the higher the waves swell, the less effective booms become. Normally booms don't operate well when waves are higher than one meter or currents are moving faster than one knot per hour. New technologies, such as submergence plane booms and entrainment inhibitors, will allow booms to operate at higher speeds, while retaining more oil.

\section{Oil spill clean-up techniques}

Once an oil spill has been contained, efforts to remove the oil from the water can begin. The main types of techniques currently available are:

- booms;

- skimmers;

- sorbents;

- dispersants;

- in-situ burning;

- bioremediation.

When used in recovering oil, booms are often supported by a horizontal arm, extending directly off one or both sides of a vessel.

Skimmers are devices used to recover floating oil from water surface. They may be self-propelled and may be used from shore or operated from vessels [5].

Sorbents are insoluble materials or mixtures of materials used to soak up liquids through the mechanism of absorption, adsorption or both. Absorbents allow oil to penetrate into pore spaces in the material they are made of, while adsorbents attract oil to their surfaces but do not allow it to penetrate into the material.

Dispersants are a group of chemicals designed to be sprayed onto oil slicks in order to accelerate the process of natural dispersion [6]. They are applied to the water surface to break up surface oil slicks and facilitate the movement of oil particles into the water column. 
Spraying dispersants may be the only means of removing oil from the sea surface, particularly when mechanical recovery is not possible. Dispersants are most effective when applied immediately following a spill, before the lightest components in the oil have evaporated. Dispersants used today are much less toxic than those used in the past.

In-situ burning involves the ignition and controlled combustion of oil; it is typically used in conjunction with mechanical recovery on open water. Fire resistant booms are often used to collect and concentrate the oil into a slick that is thick enough to burn. This technique has the potential to remove large amounts of oil from the water surface. There are a number of problems limiting the viability of this technique such as, for example, the generation of large quantities of smoke, the formation and possible sinking of extremely viscous and dense residues and safety concerns.

Oil, like many natural substances, will biodegrade over a period of time into simple compounds. The term bioremediation indicates a series of processes used to accelerate natural biodegradation [7]. Bioremediation agents are almost always applied to residual oil on shorelines, for long-term cleanup situations. Usually, heavy oil is first removed before bioremediation is undertaken. Unfortunately the practical use of bioremediation is restricted. In particular, bioremediation should not be used on oil on the sea surface, since any materials added are likely to be rapidly diluted and lost from the slick. Natural biodegradation can be most usefully accelerated when bioremediation is used on land.

Many different problems arise during the clean-up phase. For example, booms are helpful in spill containment in good weather conditions but they are not so effective in rough sea; after the skimmers have finished their work, there is still a small quantity of oil left which needs to be dispersed using for example chemical dispersants. Extra pollution is generated when using dispersants: although they are efficient in breaking up the oil slick, they contribute to the accumulation of oil products on the sea bed, thus contaminating the food chain of marine life.

An emerging method for oil spill clean-up is based on a magnetic separation technique using the material "CleanMag". The material has been developed by Prof. George Nicolaides at the Technology Education Institute of Piraeus in Greece. It is a nanocomposite magnetic material which is oleophillic and porous and has an apparent density lower than the water one. Because of its oleophillic character, the oil is quickly absorbed upon contact with the material at a weight ratio that can go up to 1:9. This material can be sprayed in granular form over the spill and can be collected from boats equipped with magnetic collection means [8].

\section{Proposed criteria for BAT selection}

Many techniques are used in order to reduce oil spill consequences. They can be essentially classified into two macro-areas:

- containment techniques;

- clean-up techniques. 
The first ones are substantially booms. The second ones encompass:

- $\quad$ booms, used in recovering oil;

- skimmers;

- sorbents;

- dispersants.

It is necessary to take into account also alternative techniques, such as:

- in-situ burning;

- bioremediation.

They have to be included rightfully in clean-up techniques. There are also emerging techniques and among those takes on a special relevance the one based upon the use of magnetic material, capable of absorbing oil. When an oil spill occurs and a technique is required to be chosen, which turns out to be suitable in the context, it would be useful that simple criteria should be readily available in order to carry out the most appropriate choice.

It is possible to identify three series of criteria that have to be applied in sequence; this means that techniques should above all comply with the criteria of the first type, after that they should meet the second type criteria and ultimately they should satisfy the third type ones:

1) main criteria;

2) technical criteria;

3) economic-environmental criteria.

Factors such as:

- $\quad$ the time of intervention;

- $\quad$ the typology of spilled oil;

- conditions at sea;

fall within the main criteria.

A very important factor when choosing the best available techniques, to face an oil spill, is the time of intervention. For example, in-situ burning should be used immediately after the actual spill, before the lighter volatile and flammable fraction has evaporated. Anyway in order to have a complete combustion, the entire oil slick should be covered with flammable substances, but this is often too difficult to carry out.

Other important factor is the typology of spilled oil that is its physicalchemical characteristics. The main oil typologies are:

- light oils;

- medium oils;

- heavy oils.

Some techniques, such as those based upon the use of dispersants have small effect on heavy crude oils. Actually heavy crude oils do not disperse as well as light and medium oils.

A main factor to take into account is represented by the conditions at sea where the spill occurred: calm sea, choppy sea, water covered with snow or ice. For example when spill occurs in water containing a layer or chunks of ice, in situ burning can often remove much more oil than conventional techniques. On the contrary, in severe sea conditions, the oil will be submerged by breaking waves, preventing direct contact between the dispersant and the oil. 
For this first group of criteria it is possible to draw a table showing the aforementioned criteria and the main containment and clean-up BATs. When a BAT satisfies each criterion an $\mathrm{X}$ is marked in the corresponding box.

Table 1: $\quad$ Main criteria.

\begin{tabular}{|c|c|c|c|c|c|c|c|c|}
\hline \multicolumn{2}{|c|}{ CRITERIA } & \multicolumn{7}{|c|}{ BAT } \\
\hline & & 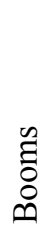 & 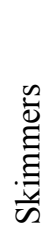 & $\begin{array}{l}\stackrel{\mathscr{0}}{0} \\
\stackrel{0}{0} \\
\stackrel{0}{0}\end{array}$ & 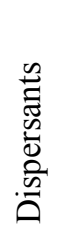 & 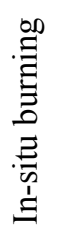 & 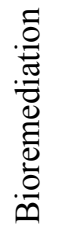 & 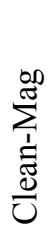 \\
\hline \multirow{2}{*}{$\begin{array}{l}\text { Time of } \\
\text { intervention }\end{array}$} & Prompt & $\mathrm{X}$ & $\mathrm{X}$ & $\mathrm{X}$ & $\mathrm{X}$ & $\mathrm{X}$ & & $\mathrm{X}$ \\
\hline & Next & $\mathrm{X}$ & $\mathrm{X}$ & $\mathrm{X}$ & & & $\mathrm{X}$ & $\mathrm{X}$ \\
\hline \multirow{3}{*}{$\begin{array}{l}\text { Typology } \\
\text { spilled oil }\end{array}$} & Light & $\mathrm{X}$ & $\mathrm{X}$ & $\mathrm{X}$ & $\mathrm{X}$ & $\mathrm{X}$ & $\mathrm{X}$ & $\mathrm{X}$ \\
\hline & Medium & $\mathrm{X}$ & $\mathrm{X}$ & $\mathrm{X}$ & $\mathrm{X}$ & $\mathrm{X}$ & $\mathrm{X}$ & $\mathrm{X}$ \\
\hline & Heavy & $\mathrm{X}$ & $\mathrm{X}$ & $\mathrm{X}$ & & $\mathrm{X}$ & $\mathrm{X}$ & $\mathrm{X}$ \\
\hline \multirow{3}{*}{ Conditions at sea } & Calm & $\mathrm{X}$ & $\mathrm{X}$ & $\mathrm{X}$ & $\mathrm{X}$ & $\mathrm{X}$ & & $\mathrm{X}$ \\
\hline & Choppy & & & & & & & $\mathrm{X}$ \\
\hline & Icy & $\mathrm{X}$ & $\mathrm{X}$ & & & $\mathrm{X}$ & & $\mathrm{X}$ \\
\hline
\end{tabular}

Afterwards, technical criteria have been identified. They take into account purely technical characteristics of the BAT such as:

- actual availability;

- feasibility;

- compatibility with other techniques.

It is noteworthy the actual availability of each technique: as a matter of fact it is necessary to verify if the technique is available in the area where oil spill occurred or if it must reach the area from considerable distance.

Another important characteristic is the technique's feasibility, in terms of logistics and other operational aspects. It is essential to check the presence of suitable trained operators and facilities in support of the technique, indispensable to the technique's carrying out.

Finally should not be neglected the compatibility of the technique, under examination, with the other ones used in the context of the operations implemented to face out the oil spill.

At last should be considered the economic-environmental criteria. They take into account costs and the impact of BATs on human health and the environment. It is possible to count among these criteria the following ones:

- the proximity of built-up areas;

- the presence of economic activities, such as fishery and tourism;

- the presence of environmental protected areas;

- the presence of submerged archaeological sites; 
- $\quad$ the loss of biodiversity;

- the cost of the technique.

Those criteria should be subdivided according to the following table 2:

Table 2: $\quad$ Economic-environmental criteria.

\begin{tabular}{|c|c|c|}
\hline \multicolumn{3}{|c|}{ ECONOMIC-ENVIRONMENTAL CRITERIA } \\
\hline \multirow{5}{*}{$\begin{array}{l}\text { IMPACT ON HUMAN } \\
\text { HEALTH AND ON } \\
\text { ENVIRONMENT }\end{array}$} & \multirow[t]{2}{*}{$\begin{array}{l}\text { Impact on } \\
\text { human health }\end{array}$} & $\begin{array}{l}\text { Proximity of built-up } \\
\text { areas }\end{array}$ \\
\hline & & $\begin{array}{l}\text { Presence of economic } \\
\text { activities }\end{array}$ \\
\hline & \multirow[t]{3}{*}{$\begin{array}{l}\text { Impact on the } \\
\text { environment }\end{array}$} & $\begin{array}{l}\text { Presence of } \\
\text { environmental protected } \\
\text { areas }\end{array}$ \\
\hline & & $\begin{array}{l}\text { Presence of submerged } \\
\text { archaeological sites }\end{array}$ \\
\hline & & Loss of biodiversity \\
\hline COSTS & \multicolumn{2}{|c|}{ Costs } \\
\hline
\end{tabular}

As far as concerns the proximity of built-up areas, these areas plainly require the use of less aggressive techniques that don't give rise to pollution, for example the atmospheric one. The closeness of built-up areas therefore excludes the possibility to employ in situ burning, because it produces huge quantities of black smoke. Clouds of black smoke may result in an oily rain, falling on such areas and leading to temporary mass evacuation.

The presence of economic activities, such as fishery and tourism, should be taken into account. In this case it would be better to use techniques acting quickly, subsequently preventing the oil spill to reach shorelines. A good technique, well satisfying this criterion, is the one based upon the use of a magnetic material, capable of absorbing oil quickly.

In some areas, and in particular in Mediterranean Sea, the possible presence of submerged archaeological sites should be taken into account. In this case are not recommended aggressive techniques, such as the one based on dispersants or in situ burning that could cause irreparable damage to these sites.

Another significant factor is the presence of marine protected areas. The same considerations, done about the previous one, apply to this criterion.

Loss of biodiversity, in the territory where oil spill happened, is the last item of the human health and environment section. Biodiversity is defined as "the variability among living organisms from all sources including, inter alia, terrestrial, marine and other aquatic systems and the ecological complexes of which they are a part" (Earth Summit - Rio de Janeiro, 1992); this includes diversity within species, between species and of ecosystems.

Loss of biodiversity has deep implications for development. Biological resources are renewable and output can be increased under appropriate management. Natural habitats which can maintain productivity without significant management have the ability to provide means for human survival. 
Conservation of biodiversity seeks to maintain the human life support system provided by nature and the living resources essential for development. Biodiversity may, therefore, be seen as an indicator of environmental health. Success in maintaining biodiversity must take into account both spatial and temporal factors. It is not, however, possible to ensure a constant level of biodiversity at a particular location over time. This item should be taken into account in all kind of impact analyses.

Therefore also in this case is not recommended the use of aggressive techniques, while it is suggested the use of mechanical containment techniques and the use of techniques such as the one based on absorbing magnetic materials.

In the end the criterion based upon the cost of the technique should not be neglected. This item includes not only the material cost of the technique, but also for example the cost for training of operators. Conditions being equal, should be clearly preferred the cheaper technique.

\section{Conclusions}

The present schematisation of BATs, used for prevention and containment of oil spills, is gathered from available international literature and from technical experience of Nature Protection Direction of Italian Ministry of Environment. The application of other innovative technique is under investigation and may lead to a further review of the schematisation as well as future improvements of the described BATs.

\section{Acknowledgements}

The authors wish to thank Dr. A. Cosentino, Chief Executive of Nature Protection Direction of the Italian Ministry of Environment, Dr. P. De Angelis and Dr. F. Cinquepalmi for their cooperation and support to the activity.

\section{References}

[1] Bilardo, U. \& Mureddu G., Traffico petrolifero e sostenibilità ambientale, Unione Petrolifera, 2004

[2] Assilzadeh, H. \& Mansor S.B., Early warning system for oil spill using SAR images. Paper presented at $22^{\text {nd }}$ Asian Conference on Remote Sensing - Singapore, 5 - 9 November 2001

[3] European Commission, http://ec.europa.eu/transport/maritime/safety /index_en.htm

[4] Mechanical Containment and Recovery of Oil Following A Spill; U.S. Environmental Protection Agency http://www.epa.gov/oilspill/pdfs /chap2.pdf

[5] Clean-up technique; International Tanker Owners Pollution Federation Limited, http://www.itopf.org/containment.html 
[6] The use of chemical dispersants to treat oil spills; Technical Information Paper; International Tanker Owners Pollution Federation Limited, http://www.itopf.com/tip4.pdf

[7] Alternative Countermeasures for Oil Spills; U.S. Environmental Protection Agency www.epa.gov/oilspill/pdfs/chap3.pdf

[8] http://www.teipir.gr/cleanmag 